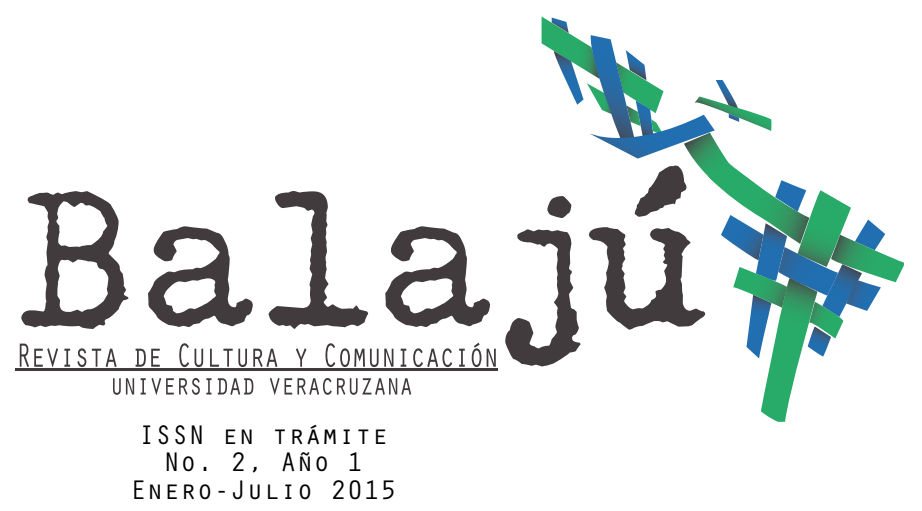

\title{
Medios, globalización y terror político: la transformación de los estudios de comunicación internacional
}

\author{
Antoni Castells i Talens* \\ Universidad Veracruzana, México \\ acastells@mac.com
}

*Doctor en Comunicación de Masas. Investigador del Centro de Estudios de Cultura y Comunicación de la Universidad Veraruzana

\section{RESUMEN}

Este ensayo explica la transformación de los estudios de la comunicación internacional desde el final de la Guerra Fría y plantea los retos que afronta la docencia de esta disciplina compleja y en constante transformación con la aparición de nuevas formas de terror político globalizado. Basado en el caso de las representaciones mediáticas de Mahoma en Europa y Estados Unidos y en sus repercusiones globales, el artículo sugiere maneras de abordar este nuevo terror político en la docencia de comunicación. La importancia de los medios en este conflicto lo convierten en un estudio de caso óptimo para actualizar la docencia de temas de comunicación internacional como conceptos de prensa y responsabilidad social; censura e intervención gubernamental en la comunicación; el flujo internacional de la información o el papel de las TIC en las relaciones internacionales.

\begin{abstract}
This essay explains the constant transformations of international communication studies since the end of the Cold War. It outlines also the challenges of teaching international communication with the appearance of new forms of globalized political terror. Based on the case of media representations of the Prophet Muhammad in Europe and the United States and their global repercussions, the article suggests possible approaches to teaching these new forms of political terror in communication courses. Because the media play a key role in the conflict, this case study can be especially useful to update the teaching of international communication topics such as concepts of the press and social responsibility; censorship and governmental intervention in mass communication; the international flow of information and communication, or the role of ICT'S in international relations.
\end{abstract}

\section{PALABRAS CLAVES}

Comunicación internacional, terror político, globalización, caricaturas de Mahoma.

\section{KEYWORDS}

International communication, political terror, globalization, Muhammad cartoons. 


\section{Medios, globalización y terror político: la transformación de los estudios de comunicación internacional}

En abril de 2015, el grupo Estado Islámico (EI) difundió la fotografía de un recién nacido durmiendo: a un lado de su cabeza reposaba una pistola y al otro, una granada. Junto a la granada, un certificado de nacimiento emitido por EI mandaba, por lo menos, tres mensajes. El primero es que el grupo, que se proclama como Estado a caballo entre Irak y Siria pero al que ningún país reconoce sino como organización terrorista ${ }^{1}$, cuenta con una estructura de gobierno con registro civil propio. El segundo, que incluso los recién nacidos en el territorio que controla se convertirán pronto en combatientes, y por lo tanto, que la guerra de EI será larga. El tercero, que no tiene intención de cesar su campaña propagandística a través de los medios para impactar y trastornar a la opinión pública mundial.

Esta fotografía venía precedida de una serie de acciones violentas durante los primeros meses de 2015, enfocadas a la cultura y la comunicación. En París, en enero, un atentado a la redacción del semanario satírico Charlie Hebdo se saldó con 12 muertos, incluyendo a algunos de los principales moneros de Francia. En Irak, militantes de EI destruyeron a mazazos estatuas y otras obras de arte milenarias en el museo de Mosul, mientras en Nimrud destrozaban esculturas de una de las principales zonas arqueológicas asirias. Semanas después, en Túnez, un grupo armado mató a 24 visitantes del Museo Nacional del Bardo, el mayor museo de Túnez y uno de los más completos de África. En abril, combatientes de Al Shabaab, un grupo asociado a Al Qaeda, entraron a una universidad en Kenya y mataron a 150 personas, la mayoría estudiantes.

Estos hechos, en el que los medios, las nuevas tecnologías y la comunicación jugaron un papel clave, son difíciles de comprender desde América Latina. La descontextualización con la que la mayoría de los medios tratan los temas relativos a conflictos internacionales como el yihadismo es sólo un reflejo de lo distante que quedan de la población latinoamericana otras partes del mundo.

Desde el final de la Guerra Fría, las ciencias sociales y los estudios de la cultura encaran el reto de analizar y explicar cambios globales en la tecnología, la economía y la política y sus impactos en la sociedad y en

1 El grupo Estado Islámico (EI) es generalmente reconocido como una escisión de Al Qaeda que en junio de 2014 se proclamó como califato situado en parte de Irak y Siria. La organización se autoconsidera un estado islámico independiente, llama a todos los musulmanes del mundo a obedecerle y pretende conquistar y controlar a mediano plazo la mitad norte de África, el Oriente Medio, las repúblicas musulmanas de Asia central, hasta Pakistán y parte de China, y algunos países de Europa del sur, incluyendo la Península Ibérica, Turquía y los Balcanes. Ningún miembro de la ONU lo ha reconocido como estado. 
la cultura a nivel local. En las últimas dos décadas, esta larga irrupción de la globalización también está cambiando la manera de entender los estudios de la comunicación, una disciplina que ha tendido al etnocentrismo. Desde sus inicios en Estados Unidos y en Europa, los problemas estudiados estaban enfocados a entender fenómenos localizados, desde la eficacia propagandística del fascismo hasta la influencia de la radio en la célebre transmisión de La Guerra de los Mundos que produjo Orson Welles o la influencia de los medios en las opciones de voto de Estados Unidos. Uno de los primeros estudios con vocación internacional, Four Theories of the Press, de Siebert, Peterson y Schramm (1956), también ha sido criticado por su etnocentrismo y, a pesar de su influencia, hoy parece ingenuo y reduccionista.

Este etnocentrismo es visible también en la mayoría de facultades y centros de comunicación universitarios, que no ofrecen cursos de comunicación internacional, y en las principales asociaciones de estudios de la comunicación, AEJMC, NCA e ICA en Estados Unidos o AMIC y CONEICC en México, donde son pocas las ponencias y publicaciones que salten las fronteras. Incluso en FELAFACS y IAMCR/AIERI, que son internacionales en vocación y estructura, se tiende más a una rica suma de temas locales que a estudios internacionales per se.

Y sin embargo, la globalización afecta tanto a la comunicación como al resto de las ciencias sociales. En el Centro de Estudios de la Cultura y la Comunicación de la Universidad Veracruzana, por ejemplo, el estudio de un objeto tan específicamente veracruzano como el son jarocho ha llevado a investigadores y estudiantes de posgrado a estudiar aspectos relacionados con la frontera, la migración y la hibridación cultural en Estados Unidos y en Europa.

Añadido al reto de estudiar una globalización que se reproduce y transforma de forma constante, los estudios de comunicación internacional encaran ahora la tarea de intentar explicar un nuevo tipo de violencia globalizada. El terror político no es nuevo, pero los objetivos que persigue y la manera de difundirlo sí. Si tradicionalmente las organizaciones armadas con fines políticos habían buscado publicidad mediática, ahora marcan la agenda no sólo de lo que es noticia, sino de qué imágenes se muestran. Ya no son los periodistas los que documentan, sino que son los mismos militantes los que producen y difunden de manera inmediata y global las imágenes del miedo, ya sea de un bebé custodiado por una granada y una pistola, ya sea de rehenes decapitados, de jóvenes crucificados o de museos destruidos. Las agencias de noticias se limitan a reproducir fotos y videos ajenos y los medios de comunicación, a editarlos, generalmente para eliminar las partes más crudas, sin poder comprobar 
su autenticidad. El uso de las redes sociales, especialmente de Twitter en el caso del grupo Estado Islámico, y de publicaciones electrónicas propias en árabe, inglés, francés y alemán, como la revista Dabiq, hacen además que los medios sean prescindibles y los mensajes del terror puedan llegar sin intermediarios a quien lo desee.

Este ensayo tiene un doble objetivo: explicar la transformación de los estudios de la comunicación internacional desde el final de la Guerra Fría y presentar los retos que afronta la docencia de esta disciplina compleja y en constante transformación con la aparición del nuevo terror político globalizado. El texto trata un conflicto que afecta de forma más directa a Europa, Estados Unidos, África y Asia que a América Latina, pero sus implicaciones alcanzan a todo el mundo. Desde hace años, por ejemplo, surgen acusaciones de que la zona fronteriza mexicana alberga campos yihadistas o de que el narco mexicano y el terror islamista han tejido una alianza, acusaciones negadas sistemáticamente por las autoridades mexicanas ${ }^{2}$. El caso analizado a continuación está escrito y enfocado desde México, basado en representaciones mediáticas realizadas desde Europa y Estados Unidos e intenta presentar la complejidad del conflicto desde varios ángulos.

Las reflexiones que surgen del texto no están pensadas en exclusiva para los estudios de la comunicación. Más bien se pueden considerar una invitación a repensar la docencia de las ciencias sociales desde una perspectiva internacional y usando una actualidad que causa desconcierto en la sociedad, y también en el estudiantado.

\section{Estudios de comunicación internacional en transformación}

La primera vez que impartí un curso en comunicación internacional, en Ursinus College, Pensilvania, no recuerdo haber mencionado la palabra globalización ni una sola vez. El término aún no circulaba entre la mayoría de los que estudiábamos la vertiente internacional de las ciencias sociales, ni mucho menos en la prensa y en la política. Aunque lo global guiaba cada clase, generalmente ligado al concepto de aldea global de McLuhan, nuestro enfoque se basaba en un esquema todavía marcado por la Guerra Fría y por un enfrentamiento dicotómico de ideologías. El Muro de Berlín había caído cinco años antes y el debate sobre el Nuevo Orden Mundial de la Información y la Comunicación (NOMIC) estaba muerto pero aún coleaba: Gran Bretaña y Estados Unidos, que habían dejado la UNESCO en los años ochenta porque percibían que el organismo se instrumentalizaba para atacar sus intereses, todavía no habían 2 J. Paullier (20 de abril de 2015). La sombra del Estado Islámico que planea sobre México. BBC. Recuperado de http://www.bbc.com/mundo 
reingresado.

Y poco después, el término globalización estalló. Se puso de moda. Los que viajábamos usábamos experiencias personales que ahora parecen banales, pero que en ese entonces causaban asombro entre los estudiantes: KFC empezaba a vender pollo en Ecuador y en México, los partidos del Futbol Club Barcelona se podían ver por televisión desde Florida y los mayas que trabajaban en Tulum, Quintana Roo, hablaban inglés y se ligaban a las turistas canadienses enseñándoles frases en maya. Para ilustrar la importancia de la globalización en lo local, Néstor García Canclini narraba el caso de un mesero mexicano al que conoció en Escocia. De entrada, García Canclini, quien se autodefinía como argentino exiliado, se encontraba haciendo antropología sobre México en Escocia. En un restaurante italiano de Edimburgo conoció a un mesero, criado en varios estados de México, que había estudiado en Estados Unidos, que también había vivido en Canadá y en París y que hablaba italiano a pesar de no haber estado nunca en Italia ${ }^{3}$. Casos similares se repetían en cada vez más ciudades y servían de ejemplos para introducir la globalización a los estudiantes.

William Hachten identificaba a una élite internacional de la información, un reducido grupo de personas que compartían un interés por la política y por la economía globales y que ejercían influencia en las políticas de todo el mundo. Según un editor transnacional, constituían "una comunidad global de gente internacional de los negocios y la política que tal vez nacieron en Londres o en Estocolmo, viven en Lagos, pero tienen más en común con alguien de Tokio que con el vecino que reside a su lado"4.

A estas élites se les estaba agregando con rapidez una serie de migrantes de todos los estratos socioeconómicos que también se movían como hormigas y que el artista Yanagi Yukinori representó de forma literal en su obra. De finales de los ochenta a principios del siglo XXI, Yukinori diseñó granjas de hormigas con banderas del mundo hechas con arena coloreada. Las banderas de arena se comunicaban por pequeños pasillos por los cuales las hormigas se iban moviendo entre ellas y agrietándolas ${ }^{5}$. Migrantes, turistas, ejecutivos, estudiantes, investigadores, empresas y capitales fungían de hormigas y mezclaban, revolvían y desordenaban unas divisiones nacionales y culturales que hasta entonces se habían presentado como claras y sólidas.

En pocos años, la globalización se convirtió en un concepto globa-

3 Néstor García Canclini, La globalización imaginada, pp. 59-60.

4 W. Hachten, The World News Prism: Changing Media of International Communication, p. 88.

5 Yanagi Studio. (2009). The World Flag Ant Farm. Recuperado de http://www.yanagistudio.net/works/antfarmproject01_view_eng.html 
lizado y omnipresente, demostrando los mismos procesos a los que denominaba, como notaba Anthony Giddens ${ }^{6}$. Los gurús de los negocios se referían a ella. Ningún discurso político se podía considerar completo sin una referencia a su presencia ${ }^{7}$. Los casos como los del mesero mexicano se volvían cada vez menos exóticos y las camisetas oficiales del Manchester United se vendían en tiendas de deportes de Guadalajara sin que los consumidores cuestionaran ya cómo se había llegado a ese punto.

La resistencia a la globalización capitalista, con una masiva manifestación de Seattle en 1999 y la aparición de una policía militarizada y represiva, como salida de una película futurista de ciencia ficción, también obligaba a cambiar de paradigma para entender la disensión social. Los nuevos movimientos sociales planteaban usos de medios horizontales, dinámicos y globales y unas gramáticas de acción innovadoras que requerían nuevas herramientas de análisis. ${ }^{8}$

El 11 de septiembre de 2001 supuso un nuevo cambio en la comunicación internacional. Los aviones, usados como armas contra las Torres Gemelas de Nueva York, convirtieron a los aeropuertos en experimentos distópicos de los Estados, que adoptaron medidas de control sin precedentes y que siguen intensificándose una década y media después. La respuesta política de control y vigilancia, la censura y el recorte de libertades civiles, la ofensiva de diplomacia pública manipulada ante la ONU y el impacto mediático del terror político a tiempo real fueron algunos de los temas que también obligaron a modificar los programas educativos. La comunicación internacional como la habíamos estudiado en el siglo XX quedaba rebasada. La Guerra Fría todavía parecía un tema indispensable para unas generaciones de estudiantes que desconocían el significado de términos como mundo bipolar, Unión Soviética o carrera armamentística y que desconocían la envergadura de lo que había representado el Muro de Berlín, pero la lógica de la Guerra Fría ya no explicaba lo que estaba sucediendo.

Ya en México, mis clases de comunicación internacional del siglo XXI se iniciaban sistemáticamente con lecturas sobre teorías de la globalización. Los libros sobre comunicación internacional estaban cambiando sus nombres para hablar de comunicación global y mis cursos también incorporaban la palabra global o globalización, dependiendo de si eran para licenciatura, maestría o doctorado, en lo que me parecía más que una moda, una manera de entender la comunicación como algo más que procesos entre estados nacionales.

Hasta la fecha, los títulos de mis clases siguen privilegiando el tér-

6 A. Giddens, Runaway World: How Globalization is Reshaping our Lives.

7 Ibid., p. 7.

8 Véase, por ejemplo, K. McDonald, Global Movements: Action and Culture. 
mino global sobre internacional, pero no estoy convencido de que comunicación internacional sea un concepto caduco que deba arrinconarse. Es cierto que ha aumentado el peso de actores supranacionales con una visión que supera el ámbito de las naciones: la Unión Europea, la Organización Mundial del Comercio, Al Qaeda y el Estado Islámico o corporaciones transnacionales como Sony, con sede en Tokyo pero con 140 ooo trabajadores y empresas subsidiarias en Estados Unidos, Australia, China, México y Alemania, entre otros países, operan a nivel global. Sin embargo, los estados nacionales siguen ejerciendo su influencia, defendiendo sus intereses y ni ellos ni los nacionalismos muestran señales de estar desapareciendo, a pesar de estar viviendo transformaciones en las formas de ejercer la soberanía y de construir sus discursos nacionales.

El regreso de la Rusia de Vladimir Putin como potencia económica y militar, su intervención en Ucrania y las tensiones permanentes con las potencias de Europa también me hacen pensar que el concepto internacional no está desfasado. No sólo es que los estados nacionales mantengan su vigencia; es que últimamente algunos de los aspectos de la comunicación y de la geopolítica de la Guerra Fría vuelven a ser útiles, aun sin una alternativa económica al capitalismo y sin enfrentamientos por la dominación global. También el regreso del autoritarismo y el aumento de casos de censura, incluso en países de tradición democrática liberal, encuentra en los regímenes autoritarios y nacionalistas del siglo XX un buen número de paralelismos.

Sea internacional o global el término de preferencia, a medida que la comunicación que trasciende fronteras se transformaba a pasos vertiginosos, impartir clases sobre el tema implicaba actualizarse semestre tras semestre. En la docena de veces que he impartido el curso, no he diseñado dos programas iguales. Uno de los grandes retos ha sido actualizar el plan de estudios con nuevos temas, sin dejar atrás temas menos actuales, pero también indispensables. Los cursos duran un semestre, y a la fuerza, cada vez que agrego un tema crucial, tiene que desaparecer otro que también lo era.

Entre los temas que no pueden desaparecer figuran: una mirada histórica a la comunicación durante la Guerra Fría, el flujo de la información (incluyendo el debate del NOMIC en la UNESCO), el imperialismo cultural, los sistemas de prensa en el mundo, la economía política de las empresas de comunicación y los barones mediáticos, las implicaciones culturales de las nuevas tecnologías de la información y los medios para el cambio social. Después se podría configurar otra lista de temas que, a pesar de su relevancia, entran y salen y vuelven a entrar en los cursos semestre tras semestre: medios y terror político, estado y vigilancia, 
propaganda internacional, comunicación y violencia, medios para la paz, medios indígenas, censura y dominación, cine e ideología, comunicación para el desarrollo, periodismo y censura en conflictos bélicos, la comunicación en movimientos revolucionarios e insurgentes, las corporaciones de relaciones públicas, la música como resistencia o el nacionalismo como discurso. Desde que la llamada guerra contra el narco en México alcanzó al estado de Veracruz y a la ciudad donde trabajo, Xalapa, el estudio de la violencia, incluyendo la militarización como discurso público y como sistema de dominación, también ha entrado en el programa. Para ello adopto un enfoque comparativo internacional, apoyándome en trabajos sobre comunicación y violencia como los de Feldman ${ }^{9}$ en Irlanda del Norte o de Clemencia Rodríguez en Colombia ${ }^{10}$.

\section{Terror político y comunicación}

A pesar de la abundante cantidad de literatura sobre comunicación en contextos de violencia, los nuevos conflictos armados, y en específico el tipo de terror político que abría este artículo, se escurren de la forma en la que se había analizado hasta hace poco. Uno de los retos docentes que supone este nuevo tipo de violencia es, de momento, de difícil solución. Una parte del terror político de hoy tiene un componente cultural y comunicacional que trasciende más allá de los mensajes propagandísticos que se estudiaban en el siglo XX. En febrero de 2015, un piloto jordano capturado por Al Qaeda fue quemado vivo mientras lo filmaban desde siete ángulos en una producción cinematográfica de estilo hollywoodense $^{11}$. El Estado Islámico ha desarrollado incluso una división de comunicación en francés e inglés, el Al Hayat Media Center, desde donde comparten videos de decapitaciones a través de Twitter. ¿Cómo se puede abordar en clase este nuevo tipo de terror mediatizado? ¿Qué teorías de la comunicación internacional o de la globalización permiten entender que la crueldad no sea escondida, maquillada o negada, como hicieron hasta cierto punto los totalitarismos del siglo XX (la Alemania de Hitler, la URSS de Stalin, la España de Franco o las dictaduras del cono sur de América), sino filmada y transmitida globalmente como espectáculo?

Desde la comunicación, también resulta difícil explicar algunos procesos de resignificación cultural. Los aviones, al igual que los trenes después del Holocausto o después de los atentados de Madrid en 2004,

9 A. Feldman, "Violence and Vision: The Prosthetics and Aesthetics of Terror", en V. Das, A. Kleinman, M. Ramphele y P. Reynolds (eds.), Violence and Subjectivity.

10 C. Rodríguez (ed.), Los que le vamos quitando a la guerra: medios ciudadanos en contextos de conflicto armado en Colombia; C. Rodríguez, Citizens' Media against Armed Conflict: Disrupting Violence in Colombia. 11 R. Fisk, (5 de abril de 2015). The Christian tragedy in the Middle East did not begin with Isis. The Independent. Recuperado de http://www.independent.co.uk 
dejan de ser medios de transporte para convertirse en símbolos de terror. La policía se militariza y los militares se policializan, haciendo que sus funciones queden cada vez menos bien definidas y que la gobernanza de la sociedad civil se rija con racionalidad y omnisciencia militares ${ }^{12}$. Algunos analistas militares también están detectando una armamentización de las redes sociales ${ }^{13}$. Como otras disciplinas, la comunicación internacional también se ve obligada a salir de su zona de confort para estudiar su propio campo de estudio. Si tradicionalmente se había apoyado en la sociología y en las relaciones internacionales, ahora posiblemente tendrá que recurrir a la antropología cultural para explicar algunos de estos procesos.

Otros retos en el análisis de este nuevo escenario pueden ser aprovechados para actualizar conceptos de comunicación y presentar a los estudiantes temas tradicionales de la comunicación internacional de manera novedosa y con sentido crítico.

Los atentados de París contra el semanario Charlie Hebdo ${ }^{14}$ eran una respuesta (una venganza, en palabra de los que cometieron los atentados) a la decisión de esta revista de publicar caricaturas de Mahoma. Algunas interpretaciones del Islam consideran que representar al profeta con imágenes es blasfemia y la revista, con trabajadores que se autodefinían como simpatizantes de la izquierda, la extrema izquierda, la anarquía y el ecologismo ${ }^{15}$, publicó las caricaturas como señal de defensa de la libertad de expresión.

Los antecedentes y las consecuencias de estas publicaciones proporcionan un estudio de caso para abordar y actualizar la docencia de temas clásicos de la comunicación internacional y al mismo tiempo, pueden activar la discusión para abordar el entendimiento del nuevo terror político.

\section{Caricaturas de Mahoma}

Las representaciones de Mahoma no son nuevas. Varios museos del mundo, incluyendo el Metropolitan de Nueva York, tienen en su colección de arte religioso obras literarias, históricas y religiosas ilustradas con imágenes del Profeta. Estas representaciones fueron "encargadas por mu-

12 S. Graham, Cities under siege: The newmilitary urbanism.

13 H. K. Gambhir (15 de agosto de 2014). Dabiq: The strategic messaging of the Islamic State. Backgrounder. Washington, D. C.: Institute for the Study of War; T. E. Nissen (2014). Terror.com: IS's social media warfare in Syria and Iraq. Contemporary Conflicts.

14 Antes del atentado de enero de 2015 mencionado al inicio de este artículo, el semanario había sido objeto de un atentado con un artefact incendiario que destrozó su redacción en 2011.

15 Charb y F. Nicolino, (20 de noviembre de 2013). Non, "Charlie Hebdo" n'est pas raciste! Le Monde. Recuperado de http://www.lemonde.fr 
sulmanes para musulmanes", sin que supusieran ninguna ofensa, sobre todo en las regiones orientales del mundo musulmán (The Metropolitan Museu of Art, sin fecha). Sin embargo, algunas interpretaciones más recientes y estrictas del Islam consideran que representar a Mahoma es blasfemia.

En 2005, el periódico conservador danés Jyllands-Posten publicó una serie de caricaturas de Mahoma, incluyendo al profeta con cuernos o con una bomba en el turbante. El incidente no atrajo la atención de los medios internacionales hasta meses después, cuando un grupo de musulmanes de Dinamarca viajó a países de tradición islámica para denunciar la blasfemia. La noticia se extendió entonces con rapidez, con manifestaciones y quemas de embajadas en varios países, causando cerca de doscientos muertos ${ }^{16}$. Varios periódicos en todo el mundo reprodujeron las caricaturas en señal de solidaridad, pero el que optó por una respuesta más irreverente fue el semanario satírico francés Charlie Hebdo, que publicó a primera plana el titular "Mahoma desbordado por los integristas”, acompañado de una caricatura de Mahoma tapándose los ojos y diciendo: "C'est dur d'être aimé par des cons..." ("Es duro ser amado por pendejos...”).

En noviembre de 2011, Charlie Hebdo presentó en línea la portada de un número especial con Mahoma de protagonista diciendo: "100 latigazos si no se mueren de la risa”. En Facebook surgieron amenazas de muerte, y justo antes del lanzamiento de la revista en los quioscos, dos personas arrojaron un cóctel molotov a la redacción del semanario, quemándola por completo. Esa misma noche, la página web de Charlie Hebdo fue hackeada y remplazada por una foto de La Meca y un mensaje en inglés que decía "No God but Allah" ("Ningún Dios que no sea Allah")"17.

Menos de un año después, en YouTube apareció un corto de 13 minutos que se suponía que era el tráiler de una película titulada Innocence of Muslims ("La inocencia de los musulmanes"). En él, Mahoma aparecía como un huérfano al que llaman "bastardo" o "Mahoma bastardo" en repetidas ocasiones, que come huesos como un animal y que se transforma en un guerrero manchado de sangre y que, empuñando una espada sangrienta, amenaza a los infieles. En pocos días, el mundo musulmán estalló en protesta contra el video. Las manifestaciones y ataques a embajadas occidentales causaron centenares de heridos y docenas de muertos en África, Asia y Europa. Google reaccionó bloqueando el acceso al video en Egipto, India, Indonesia, Malasia y otros países. Los gobiernos

16 P. Cohen, P. (12 de agosto de 2009). Yale Press Bans Images of Muhammad in New Book. The New York Times. Recuperado de http://www.nytimes.com

17 Y. Bordenave y X. Ternisien (2 de enero de 2011). Un incendie dorigine criminelle ravage les locaux de 'Charlie Hebdo'. Le Monde. Recuperado de http://www.lemonde.fr 
de Pakistán y Bangladesh, además, bloquearon totalmente el acceso a YouTube.

Cuando el conflicto del video apenas tenía una semana, el 19 de septiembre, en Francia, Charlie Hebdo publicó un nuevo dibujo de Mahoma con el profeta desnudo, echado boca abajo, y un cineasta que filmaba desde atrás. El titular leía "El film que incendia el mundo musulmán" y Mahoma decía: “¿Y mis nalgas? ¿Te gustan mis nalgas?” El mismo día, la página web de la revista recibió un ciberataque y Francia cerró embajadas, consulados, escuelas y centros culturales en 20 países musulmanes. Varias voces francesas se alzaron contra lo que vieron como una irresponsabilidad del semanario satírico. Irán bloqueó Google, YouTube y Gmail y anunció que boicotearía los Óscares de 2013 en señal de protesta ${ }^{18}$. En la ONU, un grupo de países musulmanes cabildearon para restringir la difamación de la religión y del profeta Mahoma y para excluir los ataques de carácter religioso de los temas protegidos por la libertad de expresión.

Un año y medio después, en febrero de 2014, la Suprema Corte de Justicia de Estados Unidos ordenó eliminar el video de YouTube, alegando una violación de derechos de autor de una de las actrices del video. En 2014, La inocencia de los musulmanes desapareció de Internet.

En enero de 2015, en París, dos hombres entraron a la redacción de Charlie Hebdo y mataron a 12 personas, entre los cuales figuraban los dibujantes Charb (editor de la revista), Cabu, Honoré, Tigous y Wolinski. $\mathrm{Al}$ Qaeda reivindicó en un video el atentado "como venganza por el mensajero Allah"19.

\section{Temas de debate}

Las representaciones de Mahoma ilustran hasta qué punto conflictos relacionados con la cultura y la comunicación pueden tener consecuencias dramáticas, inmediatas y globales. En la docencia de la comunicación internacional ejemplifican algunos de los temas que suele estudiar la disciplina. Los detalles de cómo explotar la riqueza de posibilidades que ofrece este caso tendrán que ser el tema de un artículo futuro, pero a continuación se esbozan algunas de ellas:

Responsabilidad social. La comunicación internacional estudia diferentes sistemas y valores de prensa. La publicación de las caricaturas se presentó como una lucha de la libertad de expresión, que en su versión satírica, es provocadora y ofensiva por definición. Otras voces, sin embargo, han abogado por un modelo de responsabilidad social, que

18 En 2012, una película iraní había ganado el Óscar a la mejor película en lengua extranjera.

19 "Al-Qaida dans la péninsule Arabique revendique l'attaque contre 'Charlie Hebdo"' (14 de enero de 2015). Le Monde. Recuperado de http://www.lemonde.fr 
evite las provocaciones para evitar la violencia. Sin defender la censura, Hervik ${ }^{20}$ argumenta que el debate de la libertad de expresión es un falso debate y que detrás de las publicaciones danesas se encuentra una ideología islamófoba y racista. Algo parecido argumentó para Charlie Hebdo un excartonista de la revista ${ }^{21}$.

Censura e intervención gubernamental. Ligado a la libertad de expresión, varios gobiernos intervinieron e intentaron influir en los medios de comunicación. Francia prohibió manifestaciones musulmanas de rechazo al video de YouTube, algunos países prohibieron el acceso a Google, la Casa Blanca presionó a Google para que eliminara el video de YouTube, el gobierno danés influyó en la construcción de framing del conflicto que respondiera a sus intereses. Las siempre complejas relaciones entre gobierno y comunicación se puede estudiar a partir de los roles jugados en este conflicto.

El flujo de la información. La manera y la dirección en que la información y la comunicación viajan entre países (agencias de noticias, satélites, publicaciones internacionales, cine, radio y televisión...) han sido de los temas más estudiados de la comunicación internacional. En los años ochenta, la tensión entre un flujo libre (sin censura ideológica) y un flujo balanceado (donde los países productores de información no usaran la comunicación para la dominación económica, cultural, ideológica o militar) desembocó en un debate en la academia, que se trasladó a la UNESCO. Ésta propuso una serie de 82 recomendaciones para balancear el flujo en lo que tenía que ser un Nuevo Orden Internacional de la Información y la Comunicación ${ }^{22}$. En señal de protesta, Estados Unidos en 1984 y Gran Bretaña en 1985 se dieron de baja de la UNESCO, cancelando su parte correspondiente de fondos para financiarla. El nuevo orden nunca se implementó y el debate en torno a él se fue apagando en los estudios de la comunicación. En esta segunda década del siglo XXI, sin embargo, medio centenar de países musulmanes representados por la Organización de la Conferencia Islámica reivindican ante la ONU que las creencias y los símbolos religiosos queden protegidos ante la burla ${ }^{23}$. De nuevo, se abre el debate sobre el control del flujo internacional de la comunicación.

Nuevas tecnologías. Tanto las ofensas a la religión como el terror político de retaliación han adquirido un componente electrónico, global e instantáneo. Twitter, Facebook, Google y YouTube son a la vez los nuevos

20 P. Hervik, "The Predictable Response to the Danish Cartoons", Global media and communication.

21 O. Cyran, (5 de diciembre 2013). Charlie Hebdo, pas raciste? Si vous le dites... Article 11. Recuperado de http://www.article11.info

22 S. McBride, Un solo mundo, voces múltiples: Comunicación e información en nuestro tiempo.

23 "Muslim countries seek global blasphemy ban" (19 de noviembre de 2009). NBC News. Recuperado de http:// www.nbcnews.com 
mensajeros y los nuevos actores políticos. En el conflicto de las representaciones de Mahoma, los gobiernos de los países involucrados no han interactuado tanto entre ellos como con Google. Estudiar el funcionamiento y las implicaciones sociales, políticas y culturales de Facebook o YouTube hace que la globalización y el flujo de la información dejen de ser temas de la cotidianidad de los estudiantes para convertirse en objetos de estudio académico. En esta nueva era, el flujo de la información, la censura y las negociaciones políticas ya no están en manos exclusivas de gobiernos, sino que incluyen a grandes transnacionales como Google.

\section{Apuntes finales}

Como se ha intentado mostrar, la docencia de temas de comunicación relacionados con el terror político puede ir más allá de la mera descripción de los hechos para intentar explicar algunas de sus causas. Por supuesto, las acciones del grupo Estado Islámico o del Al Qaeda no son exclusivamente una reacción a una ofensa satírica, aunque altamente simbólica. El terror político descrito en este trabajo es más complejo que la simple respuesta al trabajo de unos cartonistas europeos o a un video colgado en YouTube. Sus causas y motivos quedan fuera del alcance de este ensayo, y posiblemente de un curso de comunicación internacional. Sin embargo, estudiar los aspectos comunicacionales ayuda a entender parte de la naturaleza del conflicto y sus modos de operación.

Estos ejemplos muestran, además, una bidireccionalidad de la globalización. En los estudios de la globalización de los noventa, se veía cómo acciones transnacionales (una decisión de la Organización Mundial del Comercio, un tratado de libre comercio, una serie de televisión de una transnacional mediática, una política económica europea) afectaban hasta a las comunidades indígenas más alejadas de América Latina: lo global afectando lo local. En este caso, unas caricaturas publicadas en un periódico conservador de Copenhague, escrito en danés, se globalizaron para desatar un conflicto global en pocas semanas: lo local afectando lo global. 


\section{Referencias}

"Al-Qaida dans la péninsule Arabique revendique l'attaque contre 'Charlie Hebdo”" (14 de enero de 2015). Le Monde. Recuperado de http:// www.lemonde.fr

BORDENAVE, Y. y X. Ternisien (2 de enero de 2011). Un incendie d'origine criminelle ravage les locaux de 'Charlie Hebdo'. Le Monde. Recuperado de http://www.lemonde.fr

CHARB y Nicolino, F. (20 de noviembre de 2013). Non, "Charlie Hebdo" n'est pas raciste! Le Monde. Recuperado de http://www.lemonde.fr

COHEN, P. (12 de agosto de 2009). Yale Press Bans Images of Muhammad in New Book. The New York Times. Recuperado de http://www. nytimes.com

Cyran, O. (5 de diciembre 2013). Charlie Hebdo, pas raciste? Si vous le dites... Article 11. Recuperado de http://www.article11.info

FELDMAN, A. "Violence and Vision: The Prosthetics and Aesthetics of Terror”, en V. Das, A. Kleinman, M. Ramphele, y P. Reynolds (eds.), Violence and subjectivity. University of California, Berkeley, California, 2000, pp. 46-78.

FISK, R. (5 de abril de 2015). The Christian tragedy in the Middle East did not begin with Isis. The Independent. Recuperado de http:// www.independent.co.uk

GAMBHIR, H. K. (15 de agosto de 2014). Dabiq: The strategic messaging of the Islamic State. Backgrounder. Washington, D.C.: Institute for the Study of War.

GARCÍA CANCLINI, N. La globalización imaginada. Paidós, México, DF, 1999.

GIDDENS, A. Runaway World: How Globalization is Reshaping our Lives. Routledge, Nueva York, 2003.

GRAHAM, S. Cities under Siege: The Newmilitary Urbanism. Verso, Londres, 2011.

HACHTEN, W. The World News Prism: Changing Media of International Communication. 4a ed., Iowa University, Ames, Iowa, 1996.

HERVIK, P. "The Predictable Response to the Danish Cartoons", Global Media and Communication. 2 (2), 2006, pp. 225-230.

MCBRIDE, $S$. Un solo mundo, voces múltiples: comunicación e información en nuestro tiempo. Fondo de Cultura Económica, México, DF, 1987 [1980].

MCDONALD, K. Global Movements: Action and Culture. Blackwell, Malden, MA, 2006.

"Muslim countries seek global blasphemy ban" (19 de noviembre de 
2009). NBC News. Recuperado de http://www.nbcnews.com

NISSEN, T. E. "Terror.com: IS's social media warfare in Syria and Iraq", Contemporary Conflicts. 2(2), 2014, pp. 2-8.

PAULLIER, J. (20 de abril de 2015). La sombra del Estado Islámico que planea sobre México. BBC. Recuperado de http://www.bbc.com/ mundo

RODRÍGUEZ, C. (ed.). Los que le vamos quitando a la guerra: medios ciudadanos en contextos de conflicto armado en Colombia. Friedrich Ebert Stiftung, Bogotá, 2008.

. Citizens' Media against Armed Conflict: Disrupting Violence in Colombia. University of Minnesota, Minneapolis, 2011.

SIEBERT, F., T. Peterson y W. Schramm. Four Theories of the Press: The Authoritarian, Libertarian, Social Responsibility and Soviet Communist Concepts of What the Press Should Be and Do. University of Illinois Press, Chicago, 1956.

The Metropolitan Museum of Art. (sin fecha). The Prophet Muhammad and th eorigins of Islam. http://www.metmuseum.org/learn/ for-educators/publications-for-educators/art-of-the-islamic-world/ unit-one/the-prophet-muhammad-and-the-origins-of-islam

YANAGI STUDIO (2009). The World Flag Ant Farm. Recuperado de http://www.yanagistudio.net/works/antfarmprojecto1_view_eng. html 